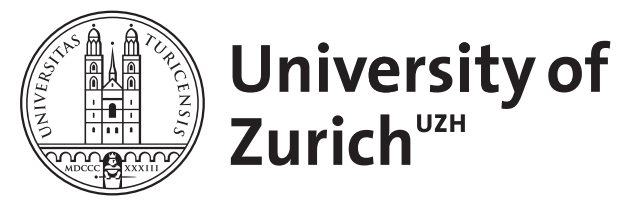

\title{
What do physicians dislike about managed care? Evidence from a choice experiment
}

\author{
Rischatsch, Maurus ; Zweifel, Peter
}

\begin{abstract}
Managed care (MC) imposes restrictions on physician behavior, but also holds promises, especially in terms of cost savings and improvements in treatment quality. This contribution reports on private-practice physicians' willingness to accept (WTA, compensation asked, respectively) for several MC features. In 2011, 1,088 Swiss ambulatory care physicians participated in a discrete choice experiment, which permits putting WTA values on MC attributes. With the exception of shared decision making and up to six quality circle meetings per year, all attributes are associated with non-zero WTA values. Thus, health insurers must be able to achieve substantial savings in order to create sufficient incentives for Swiss physicians to participate voluntarily in MC plans
\end{abstract}

DOI: https://doi.org/10.1007/s10198-012-0405-8

Posted at the Zurich Open Repository and Archive, University of Zurich ZORA URL: https://doi.org/10.5167/uzh-155881

Journal Article

Published Version

Originally published at:

Rischatsch, Maurus; Zweifel, Peter (2013). What do physicians dislike about managed care? Evidence from a choice experiment. European Journal of Health Economics, 14(4):601-613.

DOI: https://doi.org/10.1007/s10198-012-0405-8 


\title{
What do physicians dislike about managed care? Evidence from a choice experiment
}

\author{
Maurus Rischatsch • Peter Zweifel
}

Received: 10 October 2011/ Accepted: 21 May 2012/Published online: 21 June 2012

(C) Springer-Verlag 2012

\begin{abstract}
Managed care (MC) imposes restrictions on physician behavior, but also holds promises, especially in terms of cost savings and improvements in treatment quality. This contribution reports on private-practice physicians' willingness to accept (WTA, compensation asked, respectively) for several MC features. In 2011, 1,088 Swiss ambulatory care physicians participated in a discrete choice experiment, which permits putting WTA values on MC attributes. With the exception of shared decision making and up to six quality circle meetings per year, all attributes are associated with non-zero WTA values. Thus, health insurers must be able to achieve substantial savings in order to create sufficient incentives for Swiss physicians to participate voluntarily in MC plans.
\end{abstract}

Keywords Managed care - Physician preferences ·

Willingness-to-accept values - Discrete choice experiment

JEL Classification C93 $\cdot$ D61 $\cdot$ I11 $\cdot$ J22

\section{Introduction}

Many governments try to limit the rise in health care expenditure by prescribing or encouraging managed care (MC) programs. Promoting MC is one alternative to tackle expenditure; the other usually is increased copayments (Trottmann et al. [40] for a discussion of cost sharing in deregulated social health insurance). The term MC encompasses very different institutional arrangements, and

M. Rischatsch $(\square) \cdot$ P. Zweifel

Department of Economics, University of Zurich,

Hottingerstrasse 10, 8032 Zurich, Switzerland

e-mail: maurus.rischatsch@econ.uzh.ch its complexity does not allow one single broadly accepted definition (see Glied [11]). The present study uses the expression $\mathrm{MC}$ to describe the nature of the contract between ambulatory care physicians playing the role of health-care providers and health insurers as payers of care. In this case, MC contracts are defined by their specific obligations included in the contract, e.g., mandatory participation in quality circles (see "Study design" section). In mixed systems permitting choice, consumer participation in MC can be encouraged by lowered contributions to health insurance (for evidence about the reduction required to induce voluntary participation by consumers, see e.g. Zweifel et al. [44]). However, health service providers must also be won over to MC to avoid quality problems, in particular due to a lack of participating physicians. For instance, expansion of MC plans in the US has been hampered by difficulties in recruiting service providers. In Germany, the creation of so-called Integrated Care centers has been slow for the same reason. These difficulties are compounded in countries with a shortage notably of general practitioners (GPs), who play a crucial role in MC as gatekeepers. In the case of Switzerland, only about $10 \%$ of medical students intend to become GPs, while retiring GPs have difficulties finding a successor for their practice [4]. Hence, health-care reforms designed to foster MC need to address the issue of sufficient attractiveness of MC practice particularly to general practitioners.

Incentives for providers to participate in MC programs are mixed. On the one hand, they have to accept limitations of their professional autonomy, and possibly increased financial risk (especially if they participate in the financial success of the scheme). On the other hand, they can benefit from regular work hours, shared investment costs, and easier exchange of information within a network. This article purports to provide information about physicians' 
preferences, expressed as their compensation asked (willingness to accept, WTA) for departing from their conventional job characteristics without MC obligations. The evidence comes from a stated preference experiment of the discrete-choice type (DCE), performed with 1,088 Swiss private-practice physicians working in ambulatory care in 2011. The majority of respondents work in independent private practice while participating voluntarily in some MC schemes, which however account for a small share of their patients (see "Data" section). While evidence based on actual behavior would be preferable in principle, market experiments can inform policy makers and health insurers about the chances of success of planned changes, helping them avoid costly failures.

This article is organized as follows. The "Literature review" section contains an overview of the existing literature on physicians' preferences, with special reference to evidence from DCEs. The theoretical background to understand DCEs and the methods to derive WTA values are given in the "Methods" section. The "Study design" section outlines the study design and discusses the MC attributes of interest. The "Data" section describes the data. The estimation results are discussed in the "Estimation results" section, and conclusions are drawn in the "Conclusions" section.

\section{Literature review}

The existing literature on physician behavior mainly revolves around the impacts of different reimbursement systems $[18,25,27]$. The precise nature of physician preferences usually is not addressed because they do not seem to affect predictions in a substantial way. Some authors have nevertheless posited particular preferences by including professional ethics, which in principle should motivate physicians to hail MC treatment concepts such as shared decision making (SDM) and critical incident reporting (CIR) [7, 9, 43]. Attributes of professional activity originally received little attention, except for the rate of return associated with specialization [38]. More recently, Gagne and Leger [10] have examined the choice of specialty in Canada from 1976 to 1991 in response to changes in fee-for-service rates. They find income differences to be a significant factor. However, gender, mother tongue, medical school attended, state laws, and geographic conditions have a bearing on the choice of specialty as well. With the spread of MC, research into the determinants of choice of type of medical practice received new impetus. Hypothesized attributes are reputation and status [8, 29], properties of the medical practice [1], and intellectual satisfaction [8, 9]. Kristiansen [15] has claimed professional autonomy to be an additional attribute that needs to be taken into consideration. However, the relevance of these attributes, especially the non-pecuniary ones, has been little investigated.

Against the background of undersupply in rural areas of Norway, Kristiansen [16] analyzed the determinants of the decision where to locate. Place of birth, place of residency, and spouse's place of origin were found to be significant factors. However, they are not of overriding importance, causing the author to conclude that the problem of underprovision could be solved through the use of financial incentives. In addition, non-pecuniary motives might be enhanced in order to relieve the public budget, e.g. by favoring medical students with a rural background (who are particularly likely to settle there). The same conclusion is drawn by Benarroch and Hugh [2], who investigate the migration of physicians in Canada. Urbanization has a significantly positive effect on migration, whereas distance between major cities of a province has a significantly negative effect. While this research is valuable for informing policy makers about what motivates physicians to opt for existing alternatives, it is silent about their choices with regard to alternatives that are being considered but not available yet. In this situation, surveys and market experiments can fill the gap.

The effects of non-pecuniary job characteristics on physicians' labor supply decisions have mainly been surveyed in the psychological and medical literature [36]. Buddeberg-Fischer and Klaghöfer [3] examine career paths of 497 last-year medical students over a period of 8 years in Switzerland. Respondents described versatility of the field (96\%), intensive patient contact (87\%), positive experiences during their studies ( $86 \%$ ), compatibility of work with family ( $83 \%$ ), and possibilities of self-employment $(61 \%)$ as determinants of their choice of specialty. In addition, male students exhibit a preference for specialties with a scientific orientation, whereas females, for settings with intensive patient contacts. With regard specifically to MC alternatives, Nordt [26] find that conflicts due to a changed perception of the physician's professional role put more strain on practitioners in solo than in group practice. Similarly, incompatibility of work and family may be more of a problem in solo practice (2.8 out of a maximum of 5 points) than in group practice (2.3 points, difference not statistically significant).

Market experiments of the discrete-choice type (see "Study design" section below) have been performed by Scott [35] to investigate the preferences of practitioners in the UK with regard to working hours, work load, time spent on administration per week, out-of-hours appointments, and use of guidelines. Performing a DCE as well, Ubach et al. [41] report WTA values for an extra working hour per week and on being on call an extra day per month. Wordsworth et al. [42] find differences between principal 
and so-called sessional GPs. ${ }^{1}$ On the whole, the evidence is in accordance with the theoretical predictions by Marinoso and Jelovac [22], who compare the performance of gatekeeping and traditional settings, emphasizing the importance of non-financial motives for the payment of GPs to create favorable incentives.

While this research is valuable for pointing to job attributes that may be particularly valued (or resisted) by physicians, it fails to inform about their attitudes with regard to non-marginal changes. However, the transition from conventional independent private practices to contractual obligations with insurers constitutes such a nonmarginal change. Policy makers considering increasing the market share of MC through regulation as currently discussed in Switzerland need to know how much it takes to win physicians over.

\section{Methods}

Based on random utility theory [20, 21, 23, 24], discrete choice experiments (DCEs) are designed to allow individuals to express their preferences for non-marketed goods or goods that do not yet exist. The number of applications of DCEs to the valuation of health-care programs has been increasing during the past few years $[13,33,34]$. For a review of the literature on discrete choice experiments in health economics, see [5]. In a DCE, individuals are given a hypothetical choice between many or just two (binary choice) commodities. From these choices, the importance (more precisely, the expected utility) of product characteristics can be inferred. Inclusion of a cost or price attribute allows determining the valuation of the remaining product attributes in terms of money. In the present context, the price attribute is an extra payment per insured and month. The fact that respondents have to weigh several attributes simultaneously makes biases that plague contingent valuation (where individuals are asked about their willingness to pay directly, holding all other attributes constant) less likely than in a DCE [32].

The first step of a DCE involves the definition of the attributes of the commodity and the levels assigned to them $[19,33]$. Here, attributes of MC are chosen to describe the physicians' work situation (for more details, see "Study design"). When comparing hypothetical alternative MC contracts, a rational subject will choose the alternative with the higher level of utility. The decision-making process in a DCE can be seen as a comparison of utilities $U_{n i}=V_{n i}+\varepsilon_{n i}$ and $U_{n j}=V_{n j}+\varepsilon_{n j}$, where $V_{n i}$ represents

\footnotetext{
${ }^{1}$ Principal GPs have ownerships in their practice, whereas sessional GPs are freelancers (mainly young females with childcare responsibilities) and employees of NHS boards (Scotland).
}

the deterministic indirect utility of individual $n$ from alternative $i$, and $\varepsilon_{n i}$ denotes the pertaining unobserved error term. Thus, individual $n$ chooses alternative $i$ (MC) rather than alternative $j$ (conventional practice) if (and only if) $U_{n i}>U_{n j}$, which implies $V_{n i}+\varepsilon_{n i}>V_{n j}+\varepsilon_{n j}$ so that $P_{n i}=\operatorname{Pr}\left(\varepsilon_{n j}-\varepsilon_{n i}<V_{n i}-V_{n j}, \forall j \neq i\right)$. Therefore, the probability of choosing $i$ rather than $j$ implies that the error term is dominated by the systematic difference in utility.

In this study, physicians' preferences are estimated with the aid of a random-coefficient logit model (RCM) estimated by simulated maximum likelihood. The RCM has three important advantages over the standard logit model. ${ }^{2}$ First, it allows for random taste variation across physicians. Second, the RCM model permits unrestricted substitution patterns. ${ }^{3}$ Third, it allows for correlation of unobserved factors over time. The choice probabilities for the RCM are given by

$P_{n i}=\int \prod_{t=1}^{T} \frac{e^{\beta^{\prime} x_{n i t}}}{\sum_{j=1}^{J} e^{\beta^{\prime} x_{n j t}}} f(\beta \mid \theta) d \beta$,

where the logit probability is called the mixed function and $f(\beta \mid \theta)$ the mixing distribution with distribution parameters $\theta$ (see Train [39], Chap. 6). Subscript $n$ identifies the physician and $i$ the MC alternative at choice situation $t$. Preference heterogeneity is reflected by the mixing distribution $f(\beta \mid \theta)$, which is usually assumed to be normal or log-normal. The log-normal distribution serves to model a strictly positive or negative preference, e.g., for the price attribute. However, in practice the log-normal distribution may cause problems for different reasons (see "Estimation results"). Therefore, applied researchers often keep the price attribute fixed. The choice of adequate mixing distributions is important and discussed in the "Estimation results" section.

The mixing distributions reflect unconditioned or population preferences. If no choices were observed, one would only know that the coefficients follow $f(\beta \mid \theta)$. In contrast, observed choices allow conditioning the distributions of $\beta$ on the choices $(y)$, permitting the derivation of conditional or physician-specific distributions $h\left(\beta \mid y_{n}, x_{n}, \theta\right)$ of $\beta$ (see Train [39], Chap. 11). By the Bayes theorem,

$$
\begin{aligned}
h\left(\beta \mid y_{n}, x_{n}, \theta\right) & =\frac{P\left(y_{n} \mid \beta, x_{n}\right) \cdot f(\beta \mid \theta)}{\int P\left(y_{n} \mid \beta, x_{n}\right) \cdot f(\beta \mid \theta) d \beta} \\
& \propto P\left(y_{n} \mid \beta, x_{n}\right) \cdot f(\beta \mid \theta),
\end{aligned}
$$

where the denominator is the normalizing constant. $P\left(y_{n} \mid \beta, x_{n}\right)$ is the probability of physician's observed choice

\footnotetext{
$\overline{2}$ The RCM (or mixed logit) model is a generalization of the standard logit model. The RCM reduces to the standard model if density $f(\beta)=1$ for $\beta=b$ and 0 for $\beta \neq b$. Further, the random-intercept logit model (RIM, also called random-effects model) treats the constant as normally distributed with all other coefficients kept fixed.

3 This is irrelevant to this study, which is of the binary choice type.
} 
sequence $y_{n}$ given $\beta$ and the attribute levels of the chosen alternatives $x_{n}$. Hence, all quantities are known to derive $h\left(\beta \mid y_{n}, x_{n}, \theta\right)$ and to calculate moments of physicianspecific coefficients. Means can be simulated as weighted averages $\bar{\beta}=\sum_{r} w^{r} \beta^{r}$, with $w^{r}=P\left(y_{n} \mid \beta^{r}, x_{n}\right) /$ $\sum_{r} P\left(y_{n} \mid \beta^{r}, x_{n}\right)$ where $\beta^{r}$ is a draw from $f(\beta \mid \theta)$.

\section{Study design}

In this section, we present attributes related to physicians' professional activity that distinguish MC from conventional practice. Specifically, we analyze preferences for different forms of treatment concepts, critical incident reporting, quality circles, preferred provider lists, and generic drug lists.

The attribute 'treatment concepts' has two levels. First, shared decision making (SDM) requires that patients are more strongly involved in the decision-making process concerning the choice of treatment. SDM is widely applied in practice (especially encouraged by MC networks) in Switzerland, at least compared to other countries [6]. It is recommended in the medical literature as a way to make the physician a more perfect agent of the patient. An additional benefit of SDM from the point of view of a riskaverse physician is to shift the burden of proof in a malpractice suit to the (now informed) patient; however, liability suits against physicians are extremely rare in Switzerland. The downside of SDM is a certain curtailment of professional autonomy. Therefore, the valuation of SDM can go either way (see Table 1). The second level is adherence to treatment guidelines (GL), to be developed by physicians and accepted by insurers. They define how to proceed in the case of certain medical interventions. Guidelines are typical of MC; they are little known in Switzerland. They entail a strong limitation of professional autonomy combined with extra administrative work. They do shift the burden of proof in a malpractice suit to the insurer or agency (health administration) issuing them.
In view of the very low likelihood of this event, GL is expected to have a positive WTA (compensation required).

Critical incident reporting (CIR) obliges physicians to anonymously report critical incidents that happened in their practice. On the one hand, CIR calls for extra time and effort, and may give rise to fears of being interpreted as a confession of malpractice. On the other hand, CIR holds the promise of quality improvement in the treatment provided. Hence, the valuation of CIR can go either way (see Table 1).

The third attribute is the obligation to attend so-called quality circles (QC), another feature of MC. In QC, physicians meet on a regular basis to discuss new treatments and interventions as well as experiences made. This benefit to participating physicians has to be balanced against the sacrifice of time. Interviews with physician networks indicated that many of their members like to participate in QC provided they take place during lunches and are accompanied by presentations by fellow members or specialists. On the whole, no clear prediction about the expected sign of WTA can be made.

The fourth attribute is the preferred provider list (PPL), which restricts referrals to specialists and hospitals to providers selected by the MC organization. This restriction is expected to be undesired by most physicians. However, some of them may support PPL because they believe in the ability of the MC organization to identify providers offering high quality and/or high cost-efficiency.

Fifth, mandatory prescription of generic drugs if available (GEN) is imposed by most MC organizations in Switzerland. Physicians may perceive GEN as a good instrument for tackling rising drug expenditures; on the other hand, it does restrict their choice of pharmaceutical treatment. Therefore, preferences could go either way.

The sixth attribute represents the price attribute in the DCE. It is measured as a payment (PAY) over and above current income per MC-insured person per month (IPM). To be in line with microeconomic theory, all physicians should positively value PAY.

Table 1 Attributes and attribute levels in the DCE

\begin{tabular}{ll}
\hline Attribute & $\begin{array}{l}\text { Attribute levels } \\
\text { No contractual obligation to adhere to any item below versus }\end{array}$ \\
\hline Treatment concepts & $\begin{array}{l}\text { Shared decision making: yes/no (SDM, } \pm \text { ), guidelines: yes/no (GL, } \pm \text { ) } \\
\text { Critical incident reporting }\end{array}$ \\
Quality circles & Mandatory anonymous reporting: yes/no (CIR, \pm ) \\
Preferred provider list & Mandatory meetings per year: 0/3/6/12 (QC, \pm$)$ \\
Generic drug list & Referrals only to listed providers: yes/no (PPL, \pm$)$ \\
Payment & Restricted to prescribe generics if available: yes/no (GEN, \pm )
\end{tabular}

${ }^{a}$ Quality circles are defined to the last $1.5 \mathrm{~h}$ per meeting. The signs after the abbreviations in parentheses indicate our expectations about physician preferences 
Table 2 Example of choice scenario

\begin{tabular}{ll}
\hline Attribute & Obligation \\
\hline $\begin{array}{l}\text { You are to base treatment decisions on shared } \\
\text { decision making }\end{array}$ & Yes \\
$\begin{array}{l}\text { You obligate yourself to anonymously report } \\
\text { critical incidents }\end{array}$ & Yes \\
$\begin{array}{ll}\text { Number of quality circles you agree to attend per } & 6(1.5 \mathrm{~h} \text { each }) \\
\text { year } & \\
\begin{array}{l}\text { You accept a preferred provider list for referrals } \\
\text { You prescribe exclusively generics if available }\end{array} & \text { No } \\
\begin{array}{l}\text { You receive payment of } \\
\text { I am willing to sign the MC contract with these }\end{array} & \square \\
\begin{array}{l}\text { obligations } \\
\text { I would like to remain independent without }\end{array} & \square \\
\text { obligations }\end{array}$
\end{tabular}

a Payment is in CHF per insured per month (IPM). $1 \mathrm{CHF} \approx$ 1.1 USD at 2011 exchange rates

An example of a choice scenario is shown Table 2. 'Independent without obligations' defines the status quo of conventional practice, an option available to all Swiss physicians. In fact, only $13 \%$ of respondents report to be in MC practice (see "Data").

In Eq. (3) below, the attribute levels for treatment concepts (SDM, GL), critical incident reporting (CIR), preferred provider list (PPL), and generic drug list (GEN) are coded as dummy variables. Because SDM and GL are levels of one attribute, they never appear together in an alternative. Quality circles (QC) have levels of 0, 3, 6, and 12 (meetings per year). Coding them as three categorical variables (QC3, QC6, and QC12) has the advantage of not imposing a specific functional form such as the linear or quadratic. Finally, PAY denotes the payment a physician receives in return for accepting MC-type obligations, ranging from zero to $\mathrm{CHF} 2.00$ per insured and month (IPM). With an enrolment of 600 (say), this maximum corresponds to about $8 \%$ of the median monthly income [17]. Therefore, the deterministic part of the random utility can be written as

$$
\begin{aligned}
\beta^{\prime} x= & \beta_{1} \mathrm{SDM}+\beta_{2} \mathrm{GL}+\beta_{3} \mathrm{CIR}+\beta_{4} \mathrm{QC} 3+\beta_{5} \mathrm{QC} 6 \\
& +\beta_{6} \mathrm{QC} 12+\beta_{7} \mathrm{PPL}+\beta_{8} \mathrm{GEN}+\beta_{9} \mathrm{PAY} \\
& +\beta_{10} \mathrm{CONST},
\end{aligned}
$$

where the $\beta \mathrm{s}$ are the taste parameters of interest to be estimated.

The total of six attributes and their levels combine to form 480 possible combinations of alternative MC contracts. Using JMP to optimize the experimental design, this number was reduced to $40 \mathrm{D}$-optimal choice scenarios and randomly split into four groups, resulting in 10 choice situations per respondent. Each of the ten hypothetical MC contracts had to be evaluated against the reference case with no obligations imposed.

\section{Data}

The Swiss Medical Association (FMH) supported carrying out the discrete choice experiment (DCE) by including a link to the web-survey in a newsletter addressed to all members in private practice. In July 2011, a pretest involved a randomly selected sample of 1,000 FMH members. Respondents had the opportunity to write comments, which indicated a good understanding of the survey. Respondents were randomly selected considering economic and demographic characteristics to represent the ambulatory care physician community in Switzerland. The main survey was fielded in August 2011 with a return rate of $11 \%$, resulting in 10,461 observed choices by 1,088 physicians. This rate of response coincided with our expectations and previous experience with surveys addressed to physicians. A high share of $87 \%$ completed all ten choice scenarios, with 9.6 the average number of choices made per respondent. The share of respondents always choosing no obligations was $29 \%$, while $1 \%$ of physicians agreed to sign up to all MC alternatives presented. In addition to the DCE, the survey included questions about general attitudes concerning experience with MC, education, and other demographic variables.

The statistics compiled in Table 3 indicate that average age is a high 54 years (the same as the national figure, see Kraft [14]). With 26 years of experience, participants are somewhat past their halftime in independent practice on average. Accounting for $19 \%$ of the sample, women are underrepresented in the sample compared to their overall share of $32 \%$ in the medical profession [14]. The fact that relatively fewer female physicians participated in the study again coincides with previous survey experience by the Swiss Medical Association, regardless of topic. About $77 \%$ of sampled physicians are married (5\% are single, 9 divorced) and have on average 1.65 children under 18 years. Some $52 \%$ have their practice in an urban environment, while $25 \%$ are located in suburban and $23 \%$ in rural areas, respectively. The majority of respondents are from the German-speaking northern and eastern parts of Switzerland $(73 \%)$, while $24 \%$ are from the Frenchspeaking western and the remaining $3 \%$ from the Italianspeaking southern parts.

Approximately $45 \%$ of sampled physicians are general practitioners (including gynecologists and pediatricians), while $13 \%$ are specialists without surgical and $13 \%$ with surgical activity. Psychiatrists constitute $16 \%$ of the sample, while the remainder declared themselves to belong 
Table 3 Respondent descriptives, Swiss ambulatory care physicians (2011)
General practitioners include gynecologists and pediatricians.

Statistics are mean (MN), standard deviation (SD), and median (MD)

\begin{tabular}{lcclll}
\hline & & & & Percentiles & \\
\cline { 4 - 5 } Variable & MN & SD & 5th & MD & 95 th \\
\hline Age of physician & 53.73 & 8.25 & 40.00 & 54.00 & 66.00 \\
Job experience (in years) & 26.00 & 9.74 & 11.00 & 27.00 & 39.00 \\
Male respondents & 0.81 & - & - & - & - \\
Married & 0.77 & - & - & - & - \\
Number of children under 18 & 1.65 & 1.70 & 0.00 & 2.00 & 4.00 \\
Urban practices & 0.52 & - & - & - & - \\
Suburban practices & 0.24 & - & - & - & - \\
Rural practices & 0.23 & - & - & - & - \\
General practitioners & 0.45 & - & - & - & - \\
Specialists without surgery & 0.13 & - & - & - & - \\
Specialists with surgery & 0.13 & - & - & - & - \\
Psychiatrists & 0.16 & - & - & - \\
\hline
\end{tabular}

[12]. The left panel of Table 4 pertains to the randomintercept model (RIM) specification, where all coefficients are kept fixed with the exception of the constant, for which a normal distribution is assumed. The constant captures unobserved physician-specific effects. The right panel displays the parameters pertaining to the random-coefficient model (RCM), where all coefficients are assumed to be normally distributed (reflecting the theoretical expectations listed in Table 1), with the exception of a fixed coefficient for PAY. Revelt and Train [28] give three reasons for keeping the price attribute fixed. First, it facilitates the calculation of population WTA values. Second, RCM estimates tend to be unstable when all coefficients are random [31]. Third, the appropriate choice of mixing distribution for the price attribute is not straightforward. The most frequently applied log-normal distribution does often not converge in practice. Further, it renders estimates of the price coefficient that are very close to zero, causing implausibly high WTA values [37]. Therefore, the WTA values (see Fig. 1 of the "Willingness to accept MC-type obligations" section) capture only preference heterogeneity from the MC attributes but no heterogeneity with respect to PAY, and hence marginal utility of income (which may be substantial in view of the dispersion of medical income documented by Künzi et al. [17]).

The simulated log-likelihood (SLL) values at convergence are $-4,549.7$ (RIM) and $-4,261.0$ (RCM), while the AICs are 9,121.3 (RIM) and 8,559.9 (RCM), respectively. Therefore, goodness of fit speaks in favor of RCM estimates, which are emphasized in the discussion below. Table 4 shows estimated mean and standard deviation parameters along with their standard errors (SE). The mean parameters are insignificant for CIR (RIM) and six meetings per year for both specifications. All remaining parameters are highly significant with a $p$ value below 0.01 . 
Table 4 Preferences for managed care attributesregression results

\begin{tabular}{|c|c|c|c|c|c|}
\hline \multirow[t]{2}{*}{ Attribute } & \multirow[t]{2}{*}{ Parameter } & \multicolumn{2}{|c|}{$\begin{array}{l}\text { Random- intercept model } \\
\text { (RIM) }\end{array}$} & \multicolumn{2}{|c|}{$\begin{array}{l}\text { Random-coefficient model } \\
\text { (RCM) }\end{array}$} \\
\hline & & Value & SE & Value & S.E. \\
\hline \multirow[t]{2}{*}{ Shared decision making (SDM) } & Mean & 0.38 & $(0.07)$ & 0.48 & $(0.09)$ \\
\hline & SD & & & 0.95 & $(0.16)$ \\
\hline \multirow[t]{2}{*}{ Guidelines (GL) } & Mean & -0.66 & $(0.09)$ & -1.49 & $(0.19)$ \\
\hline & SD & & & 2.43 & $(0.26)$ \\
\hline \multirow[t]{2}{*}{ Critical incident reporting (CIR) } & Mean & -0.06 & $(0.06)$ & -0.16 & $(0.09)$ \\
\hline & SD & & & 0.31 & $(0.16)$ \\
\hline \multirow[t]{2}{*}{ Three quality circles (QC3) } & Mean & 0.33 & $(0.09)$ & 0.30 & $(0.11)$ \\
\hline & SD & & & 0.10 & $(0.22)$ \\
\hline \multirow[t]{2}{*}{ Six quality circles (QC6) } & Mean & 0.04 & $(0.09)$ & 0.10 & $(0.11)$ \\
\hline & SD & & & 0.79 & $(0.18)$ \\
\hline \multirow[t]{2}{*}{ Twelve quality circles (QC12) } & Mean & -0.91 & $(0.10)$ & -1.66 & $(0.18)$ \\
\hline & SD & & & 2.09 & $(0.20)$ \\
\hline \multirow[t]{2}{*}{ Preferred provider list (PPL) } & Mean & -1.42 & $(0.07)$ & -2.28 & $(0.13)$ \\
\hline & SD & & & 1.95 & $(0.14)$ \\
\hline \multirow[t]{2}{*}{ Generic drug list (GEN) } & Mean & -0.89 & $(0.07)$ & -1.66 & $(0.12)$ \\
\hline & SD & & & 2.09 & $(0.15)$ \\
\hline \multirow[t]{2}{*}{ Payment (PAY) ${ }^{\mathrm{a}}$} & Mean & 0.37 & $(0.05)$ & 0.49 & $(0.06)$ \\
\hline & SD & & & & \\
\hline \multirow[t]{2}{*}{ Constant (CONST) } & Mean & -0.73 & $(0.13)$ & -0.64 & $(0.16)$ \\
\hline & SD & 1.79 & $(0.07)$ & 1.86 & $(0.11)$ \\
\hline
\end{tabular}

a Number of physicians: 1,088 ; number of choices observed: 10,461. Coefficients for RCM are all assumed to be normally distributed, with the exception of a fixed coefficient for PAY
(88) \%. Restricting drug prescriptions to generics if available is still refused by 88 (79) $\%$. These findings suggest that with the exception of shared decision making and up to six quality circle meetings per year, all MC-type attributes have to be compensated if a majority of Swiss physicians are to be won over to MC.

\section{Willingness to accept MC-type obligations}

Next, we focus on the physician-specific willingness-toaccept (WTA) values for MC attributes, shown in Table 5. The discussion concentrates on the median values from the RCM because they are more robust to outliers than the mean values.

The negative WTA value for SDM indicates that the median Swiss physician need not to be compensated for involving patients in the decision making about choice of treatment. In contrast, following guidelines has to be compensated with about 3.57 CHF per MC-insured per month (CHF/IPM). Critical incident reporting was shown to have a small, insignificant effect on the choice probabilities (Table 4). This is reflected by a WTA value of only $0.34 \mathrm{CHF} / \mathrm{IPM}$; this low value likely reflects physicians' belief that CIR contributes to an increase in treatment quality. Quality circles are positively valued up to six meetings per year by the median respondent. Hence, including up to six quality circles in a MC contract allows 
Fig. 1 Histograms of physician-specific WTA values
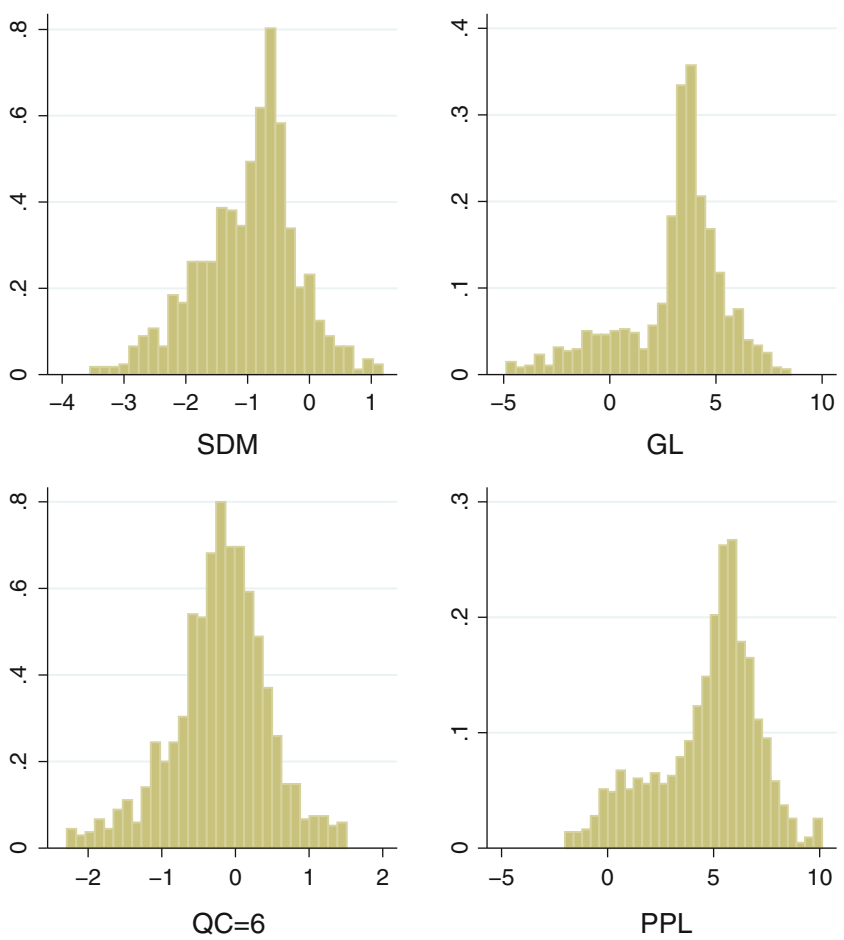
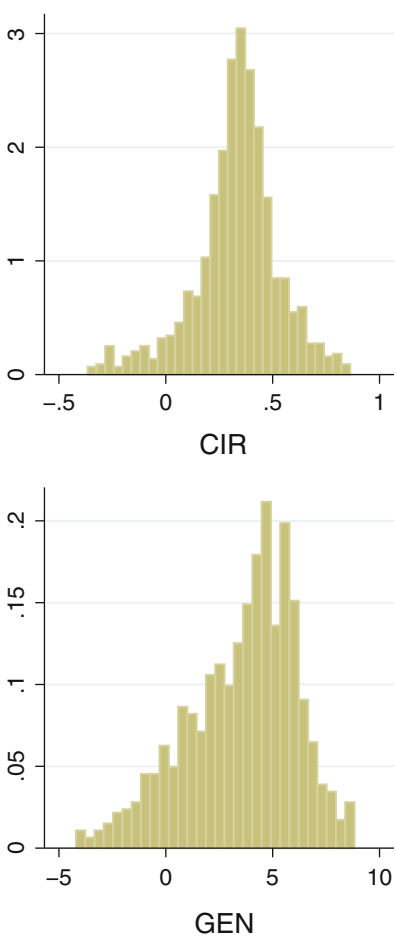

Table 5 Willingness to accept MC-type obligations

WTA values (mean denoted by $\mathrm{MN}$ and median by MD) are shown in CHF per insured and month (CHF/IPM) using physician-specific coefficients; $1 \mathrm{CHF} \approx 1.1 \mathrm{USD}$ at 2011 exchange rates

\begin{tabular}{|c|c|c|c|c|c|c|}
\hline \multirow[t]{3}{*}{ Attribute } & \multirow[t]{3}{*}{ Abbrev. } & \multirow{3}{*}{$\begin{array}{l}\text { RIM } \\
\mathrm{MN}\end{array}$} & \multicolumn{4}{|l|}{$\mathrm{RCM}$} \\
\hline & & & \multirow[t]{2}{*}{$\mathrm{MN}$} & \multirow[t]{2}{*}{ MD } & \multicolumn{2}{|c|}{ Percentiles } \\
\hline & & & & & 5 th & 95 th \\
\hline Shared decision making & SDM & -1.03 & -1.00 & -0.86 & -2.56 & 0.31 \\
\hline Guidelines & GL & 1.80 & 3.05 & 3.57 & -2.31 & 6.53 \\
\hline Critical incident reporting & CIR & 0.17 & 0.33 & 0.34 & -0.10 & 0.66 \\
\hline Three quality circles & QC3 & -0.89 & -0.61 & -0.61 & -0.73 & -0.50 \\
\hline Six quality circles & QC6 & -0.11 & -0.21 & -0.17 & -1.53 & 0.90 \\
\hline Twelve quality circles & QC12 & 2.46 & 3.46 & 3.71 & -0.83 & 6.67 \\
\hline Preferred provider list & PPL & 3.87 & 4.70 & 5.27 & -0.18 & 8.15 \\
\hline Generic drug list & GEN & 2.43 & 3.53 & 4.06 & -1.54 & 7.40 \\
\hline
\end{tabular}

reducing the overall compensation required. Nevertheless, this reduction is too low to play a crucial role in attracting physicians to participate in MC. In addition, 12 meetings already have to be compensated at the tune of $3.71 \mathrm{CHF} /$ IPM. Restricting referrals to providers listed by insurers is strongly opposed and requires the highest compensation of all MC-type attributes. Its median WTA is 5.27 CHF/IPM. The next-highest WTA value pertains to the restriction to prescribe only generics if available (GEN), with $4.06 \mathrm{CHF} / \mathrm{IPM}$. A likely reason for this high figure is the fact that about one-half of Swiss physicians live in jurisdictions permitting them to dispense drugs on their own account [30]. Therefore, the GEN attribute entails the loss of an option to generate extra income for many respondents.
In view of the entries of Table 5, the question arises of whether current extra payments by insurers suffice to win physicians over to MC. A typical value is $1.50 \mathrm{CHF} / \mathrm{IPM}$ for participating in a health maintenance organization (HMO), the most restrictive MC variant (preferred provider organizations and gatekeeping networks also exist in Switzerland). Clearly, this extra payment falls far short of what it takes to make the median Swiss physician join an HMO. To the extent that it reflects achievable cost savings due to $\mathrm{MC}$, these savings could easily be insufficient for $\mathrm{MC}$ to increase its current market share.

Because the coefficient of PAY is kept fixed, the WTA values have the same distributions as the random coefficients for the MC attributes. The histograms of Fig. 1 point to substantial heterogeneity of preferences, especially with 
regard to GL, PPL, and GEN. Opinions appear to be strongly divided concerning GL and GEN in particular, where bi-modality is evident. In the case of GEN, this likely reflects the divide between physicians who dispense drugs on their own account and those who do not.

\section{Effects of prior experience}

The preference patterns and WTA values found in the previous section do not distinguish between different groups of physicians. This section is devoted to the question of whether prior experience with a MC setting makes a difference; differences between general practitioners and specialists are discussed in the next section.

To test for differences between physicians with and without MC experience, all attributes are interacted with a dummy indicating whether respondents declared have made experience with this specific MC attribute. Table 8 of the "Appendix" (left-hand side) shows the estimated distribution parameters for the RCM containing this type of interaction. The physician-specific WTA values estimated for physicians with and without experience with the pertinent MC attribute are displayed in Table 6. In general, physicians with experience have lower WTA values, indicating less resistance against or even a preference for the MC feature. There are two reasons for this effect. First, physicians may like MC because of their favorable experience. Second, however, self-selection may be at work. Physicians with a preference for MC are likely to have selected this setting, causing them to have prior $\mathrm{MC}$ experience. As will be argued below, disentangling the two directions of causality is not worthwhile in the present policy context.

The discussion is limited to the most salient differences. They concern SDM, PPL, and GEN. First, physicians stating that they have never had experience with SDM dislike involving patients in the decision-making process. They ask for a median compensation of 0.72 CHF/IPM for SDM. In contrast, physicians with experience in SDM have a positive preference for it and do not have to be compensated. Second, physicians who have worked with a preferred provider list (PPL) exhibit a median WTA value of $2.98 \mathrm{CHF} / \mathrm{IPM}$, less than one-half of that characterizing their colleagues without that experience (6.30 CHF/IPM). Third, restricting drug prescription to generics has a median WTA of $3.72 \mathrm{CHF} / \mathrm{IPM}$ among physicians who have applied such a list, compared to 5.52 CHF/IPM for those who have not.

While it would be of scientific interest to distinguish the effect of prior experience from a possible self-selection effect, for policy makers attempting to increase the market share of MC, this is a moot point. They need to win over physicians without prior MC experience. This means that the achievable cost savings must suffice to finance the higher compensations requested by this group-letting alone the compensation asked by Swiss consumers as estimated by another DCE [44].

\section{Differences between GPs and specialists}

In the survey, physicians were asked to state if they are general practitioners (GPs, including gynecologists and pediatricians), specialists with and without surgical activities, or psychiatrists. Because GPs play a crucial role in $\mathrm{MC}$ as gatekeepers for their patients, this section compares their preferences with those of their specialized colleagues who are grouped together as 'specialists.' The same RCM is estimated as in the "Estimation results" section, but this time with MC attributes that interacted with a dummy variable, indicating whether the respondent is a specialist

Table 6 Willingness-to-accept values by experience

\begin{tabular}{|c|c|c|c|c|c|c|c|c|}
\hline \multirow[t]{3}{*}{ Attribute } & \multicolumn{4}{|c|}{ Physicians without experience } & \multicolumn{4}{|c|}{ Physicians with experience } \\
\hline & \multirow[t]{2}{*}{$\mathrm{MN}$} & \multirow[t]{2}{*}{ MD } & \multicolumn{2}{|c|}{ Percentiles } & \multirow[t]{2}{*}{ MN } & \multirow[t]{2}{*}{ MD } & \multicolumn{2}{|c|}{ Percentiles } \\
\hline & & & 5 th & 95th & & & 5 th & 95 th \\
\hline Shared decision making & 0.52 & 0.72 & -1.40 & 2.25 & -2.28 & -2.09 & -4.44 & -0.40 \\
\hline Guidelines & 3.80 & 3.85 & 1.46 & 5.55 & 0.89 & 1.22 & -2.55 & 3.19 \\
\hline Critical incident reporting & 0.72 & 0.75 & 0.13 & 1.20 & -0.35 & -0.34 & -1.54 & 0.90 \\
\hline Three quality circles & 0.37 & 0.37 & 0.30 & 0.44 & -1.32 & -1.32 & -1.59 & -1.04 \\
\hline Six quality circles & 1.59 & 1.59 & 1.54 & 1.62 & -1.39 & -1.39 & -1.44 & -1.33 \\
\hline Twelve quality circles & 5.08 & 5.18 & 1.95 & 7.45 & 2.95 & 3.05 & -1.41 & 6.57 \\
\hline Preferred provider list & 5.61 & 6.30 & -0.37 & 9.38 & 2.78 & 2.98 & -2.94 & 7.46 \\
\hline Generic drug list & 4.64 & 5.52 & -2.18 & 9.15 & 3.48 & 3.72 & -2.24 & 8.69 \\
\hline
\end{tabular}

WTA values are shown in CHF per insured per month, IPM using physician-specific WTA values from RCM, containing interactions. 'Experience' refers to the particular MC attributes listed 
Table 7 Willingness-to-accept values, general practitioners vs. specialists

\begin{tabular}{|c|c|c|c|c|c|c|c|c|}
\hline \multirow[t]{3}{*}{ Attribute } & \multicolumn{4}{|c|}{ General practitioners } & \multicolumn{4}{|c|}{ Specialists } \\
\hline & \multirow[t]{2}{*}{$\mathrm{MN}$} & \multirow[t]{2}{*}{ MD } & \multicolumn{2}{|c|}{ Percentiles } & \multirow{2}{*}{$\mathrm{MN}$} & \multirow{2}{*}{ MD } & \multicolumn{2}{|c|}{ Percentiles } \\
\hline & & & 5 th & 95 th & & & 5 th & 95 th \\
\hline Shared decision making & -0.58 & -0.55 & -1.62 & 0.46 & -1.03 & -0.70 & -4.37 & 1.07 \\
\hline Guidelines & 3.38 & 4.26 & -3.34 & 7.63 & 3.47 & 4.15 & -3.15 & 7.15 \\
\hline Critical incident report. & 0.23 & 0.24 & -0.16 & 0.59 & 0.68 & 0.78 & -0.59 & 1.46 \\
\hline Three quality circles & -0.90 & -0.90 & -0.96 & -0.85 & -0.13 & -0.12 & -0.56 & 0.27 \\
\hline Six quality circles & -0.98 & -0.98 & -1.32 & -0.64 & 0.60 & 0.60 & 0.20 & 0.96 \\
\hline Twelve quality circles & 2.50 & 2.49 & -0.12 & 4.92 & 3.61 & 3.72 & 0.93 & 5.83 \\
\hline Preferred provider list & 3.64 & 3.64 & -0.11 & 6.91 & 5.94 & 6.53 & -1.30 & 11.30 \\
\hline Generic drug list & 2.93 & 3.06 & -1.70 & 6.80 & 4.15 & 4.44 & -0.84 & 7.55 \\
\hline
\end{tabular}

WTA values are shown in CHF per insured per month, IPM using physician-specific WTA values from interacted RCM

or not. In analogy to the previous section, estimated distribution parameters are relegated to Table 8 of the "Appendix" (right-hand side). Table 7 displays the calculated physician-specific WTA values.

With regard to most MC-type attributes, WTA values do not markedly differ between GPs and specialists. There are two exceptions. One is the preferred provider list (PPL), for which the median GP would have to be compensated at the tune of 3.64 CHF/IPM, compared to $6.53 \mathrm{CHF} / \mathrm{IPM}$ for the median specialist, the overall maximum found in this study. This discrepancy is intuitive for three reasons. First, a specialist who joins a MC network depends on referrals from GPs (potentially governed by a PPL) in an even more decisive way than in conventional practice, whereas referrals play a minor role in either setting for a GP. Second, many specialists serve more than one MC network, in which case a PPL imposed by one of the networks can hurt them. By way of contrast, GPs typically work for a single MC organization; there is no need for them to rely on demand emanating from other MC organizations. Finally, specialized physicians may feel that they know better than GPs which providers to choose for their patients or networks. The second discrepancy concerns the generic drug list (GEN), where GPs have to be compensated with a median of $3.06 \mathrm{CHF} / \mathrm{IPM}$, but specialists with $4.44 \mathrm{CHF} /$ IPM. A likely explanation is that specialists are more likely than GPs to treat rare diseases that might call for a brandname drug, which is not listed.

On the whole, general practitioners are found to be less strongly opposed to attributes of MC. Thus, winning them over to MC is less costly than estimated in "Estimation results" section based on the whole sample. Still, a payment of $1.50 \mathrm{CHF} / \mathrm{IPM}$ remains insufficient for attracting a majority of GPs to an MC organization that imposes guidelines requiring more than six quality circle meetings per year, a preferred provider list, or a generic drug list.

\section{Conclusions}

Policy makers try to limit increasing health care expenditure by mandating or encouraging Managed Care (MC). However, attempts to increase the market share of MC often fail because of a lack of participating physicians. As long as conventional practice remains an alternative, health service providers must be won over to MC because they have to accept limitations of their professional autonomy. The objective of this contribution is to investigate physicians' preferences for MC attributes measured as willingness-to-accept (WTA) values. The data come from a sample of 1,088 Swiss private-practice physicians working in ambulatory care participating in a discrete choice experiment (DCE) in 2011.

The MC attributes studied are shared decision-making and guidelines; reflecting treatment concepts; critical incident reporting; attending $0,3,6$, or 12 quality circle meetings per year, accepting a preferred provider list, and having drug prescription restricted to generics if available. To determine the money valuation of MC attributes expressed as WTA values, a price attribute is included, defined as a payment per MC-insured per month (IPM) to compensate the physician for additional cost and effort.

Estimated distribution parameters for the random-coefficient model show that the median Swiss physician likes shared decision making, three quality circles, and payment; is indifferent with regard to six quality circles per year; and dislikes all other MC attributes. The highest share of opposing physicians is found for the preferred provider list. All respondents like three quality circles per year. With respect to strength of opposition, estimated WTA values reveal that preferred provider and generic drug lists have to be compensated most, with median WTA ranging from $3.60 \mathrm{CHF} / \mathrm{IPM}$ to $5.30 \mathrm{CHF} / \mathrm{IPM}(1 \mathrm{CHF} \approx 1.1 \mathrm{USD}$ in 2011). These figures exceed the current level of $1.50 \mathrm{CHF} /$ IPM, which already amounts to $8 \%$ of median physician 
income. Shared decision making and up to six quality circles are accepted without compensation.

Clear signs of preference heterogeneity motivate distinctions between physician groups. For an expansion of MC, physicians without prior experience with MC-type attributes need to be attracted. However, some of their WTA values turn out to be twice as high as those of physicians with prior experience. Another distinction of importance is between general practitioners and specialists since some MC organizations have difficulty offering the full range of specialties. Indeed, specialists are found to exhibit higher WTA values than GPs almost without exception; their resistance against a preferred provider list would have to be overcome by a payment of $6.53 \mathrm{CHF} / \mathrm{IPM}$, the overall maximum found in this study. Considering that a current rate for participating in an HMO is $1.50 \mathrm{CHF} / \mathrm{IPM}$, these findings lead to the prediction that $\mathrm{MC}$ plans designed to achieve cost savings are unlikely to enlist the majority of Swiss physicians as long as they retain the option of conventional practice with full professional autonomy. Realistically, the implementation of shared decision making, critical incident reporting, and up to six quality circle meetings per year can be expected. It is doubtful that future cost savings achievable through treatment guidelines, a preferred provider list, and generic drug lists are of a magnitude that would permit the current 1.50 CHF/IPM to be doubled or even tripled, reaching compensation amounts that would render MC attractive to the median physician. Prospects for a voluntary, market-driven expansion of MC in Switzerland look rather bleak indeed; quality circles as the one positively valued attribute do not modify this conclusion.

Acknowledgements The authors would like to express their thanks to Dr. med. Jacques de Haller and Dr. med. Ignazio Cassis from the Swiss Medical Association (FMH) for making the experiment for the present analysis possible. Support by Martina Hersperger and Esther Kraft is also gratefully acknowledged. Special thanks go to Dr. Maria Trottmann and Dr. Harry Telser for their very helpful comments.

\section{Appendix}

See Table 8 .
Table 8 Preferences for managed care attributes (model with interactions)

\begin{tabular}{|c|c|c|c|c|c|}
\hline \multirow[t]{2}{*}{ Attribute } & \multirow[t]{2}{*}{ Parameter } & \multicolumn{2}{|c|}{ Experience } & \multicolumn{2}{|c|}{ Profession } \\
\hline & & Value & SE & Value & SE \\
\hline \multirow[t]{2}{*}{ Shared decision making } & Mean & -0.24 & $(0.14)$ & 0.28 & $(0.11)$ \\
\hline & SD & 1.14 & $(0.16)$ & 0.71 & $(0.16)$ \\
\hline \multirow[t]{2}{*}{ SDM interacted } & Mean & 1.32 & $(0.17)$ & 0.18 & $(0.18)$ \\
\hline & SD & 0.35 & $(0.96)$ & 1.30 & $(0.27)$ \\
\hline \multirow[t]{2}{*}{ Guidelines } & Mean & -1.71 & $(0.22)$ & -1.55 & $(0.24)$ \\
\hline & SD & 1.30 & $(0.32)$ & 2.65 & $(0.26)$ \\
\hline \multirow[t]{2}{*}{ GL interacted } & Mean & 1.25 & $(0.26)$ & -0.07 & $(0.31)$ \\
\hline & SD & 0.91 & $(0.38)$ & 0.79 & $(0.34)$ \\
\hline \multirow[t]{2}{*}{ Critical incident reporting } & Mean & -0.34 & $(0.10)$ & -0.11 & $(0.11)$ \\
\hline & SD & 0.37 & $(0.17)$ & 0.34 & $(0.24)$ \\
\hline \multirow[t]{2}{*}{ CIR interacted } & Mean & 0.54 & $(0.18)$ & -0.22 & $(0.17)$ \\
\hline & SD & 0.72 & $(0.28)$ & 0.61 & $(0.26)$ \\
\hline \multirow[t]{2}{*}{ Preferred provider list } & Mean & -2.50 & $(0.14)$ & -1.62 & $(0.13)$ \\
\hline & SD & 2.22 & $(0.18)$ & 1.49 & $(0.20)$ \\
\hline \multirow[t]{2}{*}{ PPL interacted } & Mean & 1.07 & $(0.31)$ & -0.95 & $(0.21)$ \\
\hline & SD & 0.36 & $(0.43)$ & 2.09 & $(0.22)$ \\
\hline \multirow[t]{2}{*}{ Generic drug list } & Mean & -2.10 & $(0.19)$ & -1.31 & $(0.14)$ \\
\hline & SD & 2.48 & $(0.24)$ & 1.71 & $(0.14)$ \\
\hline \multirow[t]{2}{*}{ GEN interacted } & Mean & 0.41 & $(0.23)$ & -0.56 & $(0.20)$ \\
\hline & SD & 0.41 & $(0.29)$ & 0.65 & $(0.17)$ \\
\hline \multirow[t]{2}{*}{ Three quality circles } & Mean & -0.17 & $(0.16)$ & 0.42 & $(0.13)$ \\
\hline & SD & 0.04 & $(0.29)$ & 0.04 & $(0.20)$ \\
\hline \multirow[t]{2}{*}{ QC3 interacted } & Mean & 0.78 & $(0.18)$ & -0.37 & $(0.17)$ \\
\hline & SD & 0.15 & $(0.19)$ & 0.31 & $(0.29)$ \\
\hline \multirow[t]{2}{*}{ Six quality circles } & Mean & -0.73 & $(0.17)$ & 0.46 & $(0.14)$ \\
\hline & SD & 0.03 & $(0.23)$ & 0.23 & $(0.27)$ \\
\hline
\end{tabular}


Table 8 continued

\begin{tabular}{|c|c|c|c|c|c|}
\hline \multirow[t]{2}{*}{ Attribute } & \multirow[t]{2}{*}{ Parameter } & \multicolumn{2}{|c|}{ Experience } & \multicolumn{2}{|c|}{ Profession } \\
\hline & & Value & SE & Value & SE \\
\hline \multirow[t]{2}{*}{ QC6 interacted } & Mean & 1.37 & $(0.19)$ & -0.75 & $(0.19)$ \\
\hline & SD & 0.01 & $(0.24)$ & 0.10 & $(0.24)$ \\
\hline \multirow[t]{2}{*}{ Twelve quality circles } & Mean & -2.33 & $(0.25)$ & -1.15 & $(0.18)$ \\
\hline & SD & 1.45 & $(0.25)$ & 1.26 & $(0.24)$ \\
\hline \multirow[t]{2}{*}{ QC12 interacted } & Mean & 0.94 & $(0.27)$ & -0.49 & $(0.23)$ \\
\hline & SD & 1.24 & $(0.34)$ & 0.59 & $(0.25)$ \\
\hline \multirow[t]{2}{*}{ Constant } & Mean & -0.56 & $(0.16)$ & -0.42 & $(0.15)$ \\
\hline & SD & 1.76 & $(0.11)$ & 1.77 & $(0.09)$ \\
\hline Payment & Mean & 0.46 & $(0.06)$ & 0.47 & $(0.06)$ \\
\hline
\end{tabular}

\section{References}

1. Beardow, R., Cheung, K., Styles, W.: Factors influencing the career choices of general practitioner trainees in North West Thames Regional Health Authority. Br. J. General Pract. 143, 449-452 (1993)

2. Benarroch, M., Hugh, G.: The interprovincial migration of Canadian physicians: does income matter?. Appl. Econ. 36(20), 2335-2345 (2004)

3. Buddeberg-Fischer, B., Klaghöfer, R.: Geschlecht oder Persönlichkeit? Determinanten der Karrierepläne angehender Ärztinnen und Ärzte. (Gender or personality? Determination of career plans of future physicians). In: Abele A., Hoff E.-H., Hohner H.-U. (eds). Frauen und Männer in akademischen Professionen. Berufsverläufe und Berufserfolg (2003)

4. Buddeberg-Fischer, B., Klaghöfer, R., Stamm, M., Marty, F., Dreiding, P., Zoller, M., Buddeberg, C.: Primary care in Switzerland-no longer attractive for young physicians? Swiss Med. Wkly. 136, 416-424 (2006)

5. De Becker-Grob, E.W., Ryan, M., Gerard, K.: Discrete choice experiments in health economics: a review of the literature. Health Econ. doi:10.1002/hec.1697 (2010)

6. Deveugele, M., Derese, A., van den Brink-Muinen, Bensing, J., De Maeseneer, J.: Consultation length in general practice: cross sectional study in six European countries. Bri. Med. J. 325, 472-478 (2002)

7. Dionne, G., Contandriopoulos, A.: Doctors and their workshops: a review article. J. Health Econ. 4, 21-33 (1985)

8. Enthoven, A.: Consumer-choice health plan. N. Engl. J. Med. 298(22), 1223-1238 (1978)

9. Feldstein, M.: The rising price of physicians' services. Rev. Econ. Stat. 52, 121-133 (1970)

10. Gagne, R., Leger, P.: Determinants of physicians' decision to specialize. Health Econ. 14(7), 721-735 (2005)

11. Glied, S.: Managed care. In: Culyer, A.J., Bewhouse, J.P. (eds.) Handbook of Health Economics, vol. 1, Chap. 13, pp. 707-753. North-Holland Publishing Company, Amsterdam (2000)

12. Hole, A.: Fitting mixed logit models by using maximum simulated likelihood. Stata J. 7(3), 388-401 (2007)

13. Hole, A.: Modelling heterogeneity in patients' preferences for the attributes of a general practitioner appointment. J. Health Econ. 27, 1078-1094 (2008)

14. Kraft, E.: 30 '273 Ärztinnen und Ärzte für die Schweiz (30,273 physicians for Switzerland). Schweizer Ärztezeitung 92(12), 440-444 (2010)
15. Kristiansen I.: What is in the doctor's utility function? A theoretical and empirical investigation into what influences doctors' decision making. Dissertation, University of Tromso (1994)

16. Kristiansen, I.: Medical specialists' choice of location: the role of geographical attachment in Norway. Soc. Sci. Med. 34(1), 57-62 (1992)

17. Künzi, K., Strub, S., Stocker, D.: Erhebung der Einkommenverhältnisse der berufstätigen Ärtzeschaft (Census of earning capacity of the working medical fraternity). Schweizerische Ärztezeitung 92(36), 1361-1366 (2011)

18. Labelle, R., Stoddart, G., Rice, T.: A re-examination of the meaning and importance of supplier-induced demand. J. Health Econ. 13, 347-368 (1994)

19. Louviere, J.J., Hensher, D.A., Swait, J.D.: Stated Choice Methods. Analysis and Applications. University Press, Cambridge (2000)

20. Luce, D.: Individual Choice Behavior. Wiley, New York (1959)

21. Manski, C.F.: The structure of random utility models. Theor. Decis. 52, 229-254 (1977)

22. Marinoso, B., Jelovac, I.: GPs' payment contracts and their referral practice. J. Health Econ. 22(4), 617-635 (2003)

23. McFadden, D.: Econometric models of probabilistic choice. In: Manski, C., McFadden, D. (eds) Structural Analysis of Discrete Data with Applications, pp. 198-272. The MIT Press, Cambridge (1981)

24. McFadden, D.: Economic choices. Am. Econ. Rev. 91, 351-378 (2001)

25. McGuire, T.G.: Physician agency. In: Culyer, A.J., Newhouse, J.P. (eds) Handbook of Health Economics, vol. 1, Chap. 9, pp. 461-536. North-Holland Publishing Company, Amsterdam (2000)

26. Nordt, C.: Strukturwandel der medizinischen Grundversorgung. Ursachen und Wirkungen der ärztlichen Arbeitszufriedenheit in unterschiedlichen Praxismodellen. (Structural changes in primary medical practice. Determinants and consequences of physicians' job satisfaction in different settings). Dissertation, submitted for the Factulty of Philosophy, University of Zurich (2003)

27. Pauly, M.: Editorial: A re-examination of the meaning and importance of supplier-induced demand. J. Health Econ. 13, 369-372 (1994)

28. Revelt, D., Train, K.E.: Customer-specific taste parameters and mixed logit. Working paper (1999)

29. Richardson, J.: The inducement hypothesis: that doctors generate demand for their own service. In: Gaag, J., Perlman, M. (eds) Health, Economics and Health Economics., pp. 189-214. NorthHolland Publishing Co., Amsterdam (1981) 
30. Rischatsch, M., Trottmann, M., Zweifel, P.: Generic substitution, financial interests, and imperfect agency. Working paper (2010)

31. Ruud, P.: Simulation of the multinomial probit model: An analysis of covariance matrix estimation. working paper (1996)

32. Ryan, M.: A comparison of stated preference methods for estimating monetary values. Health Econ. 13(3), 291-296 (2004)

33. Ryan, M., Gerard, K.: Using discrete choice experiments to value health care programmes: current practice and future reflections. Appl. Health Econ. Health Policy 2(1), 55-64 (2003)

34. Scanlon, D., Chernew, M., Lave, J.: Consumer health plan choice. Annu. Rev. Public Health 18, 507-528 (1997)

35. Scott, A.: Eliciting GPs' preferences for pecuniary and nonpecuniary job characteristics. J. Health Econ. 20, 329-347 (2001)

36. Scott, A.: Giving things up to have more of others. the implications of limited substitutability in eliciting preferences for health and health care. Discussion paper 01/98, Health Economics Research Unit, University of Aberdeen (1998)

37. Sillano, M., Ortuzar, J.D.D.: Willingness-to-pay estimation with mixed logit models:some new evidence. Environ Plann. A 37, 525-550 (2005)
38. Sloan, F.: The demand for higher education: the case of medical school applicants. J. Human Resour. 6(4), 466-489 (1971)

39. Train, K.E.: Discrete Choice Methods with Simulation. University Press, Cambridge (2003)

40. Trottmann, M., Zweifel, P., Beck, K.: Supply-side and demandside cost sharing in deregulated social health insurance: which is more effective?. J. Health Econ. 31, 231-242 (2012)

41. Ubach, C., Scott, A., French, F., Awramenko, M., Needham, G.: What do hospital consultants value about their job? A discrete choice experiment. Br. Med. J. 326, 1432-1438 (2003)

42. Wordsworth, S., Skatun, A., Scott, A., French, F.: Preferences for general practice jobs: a survey of principals and sessional GPs. Br. J. Gen. Pract. 54(507), 740-746 (2004)

43. Zweifel, P.: Supplier-induced demand in a model of physician behavior. In: Gaag, J., Perlman, M. (eds) Health, Economics and Health Economics, North-Holland Publishing Co., Amsterdam (1981)

44. Zweifel, P., Telser, H., Vaterlaus, S.: Consumer resistance against regulation: the case of health care. J. Regul. Econ. 29(3), 319-332 (2006) 